newborn: $3(30 \%)$ prenatally, $4(40 \%)$ by physical examination before discharge and 3(30\%) after hospital discharge. Since pulseoximetry screening (May 2013), there have been 4 patients (out of 3068 deliveries) with CCHD, all of them diagnosed before hospital discharge ( 2 prenatally, 2 by physical examination and pulseoximetry). There were 2 false positives (0,06\%), one of them was diagnosed of situs inversus totalis, probably related to Kartagener syndrome.

Conclusion Conventional screening for congenital heart disease can lead to a significant rate of unrecognised CCHD. Pulseoximetry may be a useful screening test, false-positive rate was particularly low $(<0,1 \%)$.

More studies are needed to assess its long-term real value and economic impact in our heath system.

\section{PO-0509 FUNCTIONAL ECHOCARDIOGRAPHY AND MULTISITE TISSUE OXYGENATION MONITORING IN PRETERM INFANTS WITH CLINICAL SEPSIS}

${ }^{1}$ ME van der Laan, ${ }^{2}$ MTR Roofthooft, ${ }^{1}$ TE Schat, ${ }^{1}$ AF Bos, ${ }^{2}$ RMF Berger, ${ }^{1}$ EMW Kooi. ${ }^{1}$ Divison of Neonatology, Beatrix Children's Hospital University Medical Center Groningen, Groningen, Netherlands; ' ${ }^{2}$ Divison of Pediatric Cardiology, Beatrix Children's Hospital University Medical Center Groningen, Groningen, Netherlands

\subsection{6/archdischild-2014-307384.1153}

Background Diagnosing circulatory failure in preterm infants with sepsis is challenging. Multisite Near-infrared spectroscopy (NIRS) monitoring and functional echocardiography are noninvasive tools to assess micro- and macro circulation. Our aim was to assess the correlation between both monitoring methods in preterm infants with clinical sepsis.

Methods Prospective exploratory cohort study. We included preterm infants with clinical sepsis. Functional echocardiography was performed twice, once within $48 \mathrm{~h}$ of sepsis work-up and once at least $24 \mathrm{~h}$ later. We measured cerebral, renal, and intestinal tissue oxygen saturation using NIRS during an hour of stable measurements directly preceding or following echocardiography and calculated fractional tissue oxygen extraction (FTOE) in each tissue. We determined Spearman's correlation coefficients between the FTOE and right ventricular output (RVO), left ventricular output (LVO), superior vena cava flow (SVC-flow), ductus arteriosus flow (DA-flow) and patent foramen ovale flow (PFO-flow).

Results We included 24 infants (median GA=27.7 wks, $\mathrm{BW}=928 \mathrm{~g}, \quad \mathrm{PNA}=11.8 \mathrm{~d})$. In seven infants only the first

Abstract P0-0509 Table 1 Association expressed as spearman's $\mathrm{p}$ between (deltea) NIRS measurements and (delta) flow measurements

\begin{tabular}{|c|c|c|c|c|c|c|c|}
\hline $\begin{array}{l}\text { First } \\
\text { echo }\end{array}$ & SETOE & FTTOE & IFTOE & $\begin{array}{l}\text { Changes } \\
\text { between } \\
\text { echo's }\end{array}$ & dCFTOE & drFTOE & diFTOE \\
\hline RVO & $\begin{array}{l}-0.014 \\
\mathrm{~N}=22\end{array}$ & $\begin{array}{l}0.186 \\
N=22\end{array}$ & $\begin{array}{l}-0.509 \\
N=11\end{array}$ & dRVQ & $\begin{array}{l}0.1 \$ 1 \\
N=13\end{array}$ & $\begin{array}{l}0.000 \\
N=12\end{array}$ & $\begin{array}{l}-0.500 \\
N=8\end{array}$ \\
\hline LVO & $\begin{array}{l}-0.167 \\
\mathrm{~N}=24\end{array}$ & $\begin{array}{l}0.429^{2} \\
\mathrm{~N}=24\end{array}$ & $\begin{array}{l}-0.385 \\
N=13\end{array}$ & dLVO & $\begin{array}{l}0.332 \\
\mathrm{~N}=15\end{array}$ & $\begin{array}{l}0.288 \\
\mathrm{~N}=14\end{array}$ & $\begin{array}{l}-0.483 \\
N=9\end{array}$ \\
\hline DA-tlow & $\begin{array}{l}-0.028 \\
N=24\end{array}$ & $\begin{array}{l}0.267 \\
N=24\end{array}$ & $\begin{array}{l}0.309 \\
\mathrm{~N}=13\end{array}$ & dDA-flow & $\begin{array}{l}-0.174 \\
N=17\end{array}$ & $\begin{array}{l}0.197 \\
\mathrm{~N}=16\end{array}$ & $\begin{array}{l}0.000 \\
\mathrm{~N}=11\end{array}$ \\
\hline $\begin{array}{l}\text { Svc: } \\
\text { flow: }\end{array}$ & $\begin{array}{l}-0.207 \\
\mathrm{~N}=22\end{array}$ & $\begin{array}{l}0.020 \\
N=22\end{array}$ & $\begin{array}{l}0.608^{12} \\
N=12\end{array}$ & $\begin{array}{l}\text { dSVC: } \\
\text { flow }\end{array}$ & $\begin{array}{l}-0.227 \\
N=11\end{array}$ & $\begin{array}{l}0.236 \\
N=11\end{array}$ & $\begin{array}{l}-0.500 \\
\mathrm{~N}=8\end{array}$ \\
\hline BEO-tlow & $\begin{array}{l}0.380 \\
N=20\end{array}$ & $\begin{array}{l}0.128 \\
N=20\end{array}$ & $\begin{array}{l}0.091 \\
N=10\end{array}$ & $\begin{array}{l}\text { dPFO- } \\
\text { flow }\end{array}$ & $\begin{array}{l}-0.081 \\
N=12\end{array}$ & $\begin{array}{l}-0.112 \\
\mathrm{~N}=12\end{array}$ & $\begin{array}{l}-0.810^{\pi} \\
\mathrm{N}=8\end{array}$ \\
\hline $\begin{array}{l}\text { RVO- } \\
\text { PFO }\end{array}$ & $\begin{array}{l}-0.233 \\
\mathrm{~N}=19\end{array}$ & $\begin{array}{l}0.156 \\
N=19\end{array}$ & $\begin{array}{l}-0.700^{2} \\
N=9\end{array}$ & $\begin{array}{l}\text { dRVQ. } \\
\text { PFO }\end{array}$ & $\begin{array}{l}0.200 \\
N=11\end{array}$ & $\begin{array}{l}-0.027 \\
N=11\end{array}$ & $\begin{array}{l}-0.250 \\
N=7\end{array}$ \\
\hline LVO-DA & $\begin{array}{l}-0.184 \\
\mathrm{~N}=24\end{array}$ & $\begin{array}{l}0.106 \\
N=24\end{array}$ & $\begin{array}{l}-0.604^{\pi} \\
N=13\end{array}$ & dLVO-DA & $\begin{array}{l}0.514^{\pi} \\
N=15\end{array}$ & $\begin{array}{l}0.046 \\
N=14\end{array}$ & $\begin{array}{l}-0.250 \\
N=9\end{array}$ \\
\hline
\end{tabular}

echocardiography was performed. Correlation coefficients between (changes in) NIRS-measurements and (changes in) functional echocardiography measurements are displayed in Table 1. Conclusion RVO-PFO and LVO-DA flow, indicators of systemic blood flow in preterm infants with shunts, were negatively associated with intestinal FTOE, but not with renal and cerebral FTOE. This indicates that a compromised macro circulation in preterm infants with clinical sepsis is associated with low intestinal but not cerebral or renal perfusion. Furthermore, our results suggest that macro circulatory changes during sepsis do not cooccur with changes in microcirculatory indices in various organs.

\section{PO-0510 INHIBITION OF PENTOSE PHOSPHATE PATHWAY AND NADPH OXIDASE IMPAIRED THE RESPONSE OF CHICKEN DUCTUS ARTERIOSUS TO OXYGEN}

E Tserga, MM Goorts, E Villamor. Pediatrics, Maastricht University Medical Center, Maastricht, Netherlands

\subsection{6/archdischild-2014-307384.1154}

Introduction NADPH derived from the pentose phosphate pathway (PPP) is a key system involved in maintaining the function of several important redox and antioxidant defense mechanisms. NADPH oxidases contain a catalytic NOX subunit that transfers electrons from NADPH to oxygen, thereby forming reactive oxygen species (ROS). Normoxic contraction of the ductus arteriosus (DA), such as occurs at birth, appears to be dependent upon the increase of ROS in DA smooth muscle cells. We hypothesised a role for NOX-derived ROS in the signalling pathway of oxygen-induced contraction of the DA.

Methods We investigated the effects of the inhibition of PPP and NOX in the ex vivo response of chicken DA to oxygen. Experiments were performed in myograph-mounted DA rings (pulmonary and aortic sides) isolated from chicken embryos incubated for 19 days (total incubation: 21-d).

Results Exposure to oxygen (21\%) induced a sustained contractile response in the pulmonary but relaxation in the aortic side of 19-d DA. Incubation with the PPP inhibitor epiandrosterone or with the NOX inhibitors GKT-136901, VAS2870 and VAS3947 elicited a partial or complete impairment of oxygeninduced contraction. Phenylephrine- and $\mathrm{KCl}$-induced contraction of chicken DA were impaired by epiandrosterone and VAS3947 but not by the other NOX inhibitors. Moreover, VAS3947 evoked an irreversible impairment of the contractility of the vessel. Oxygen-induced relaxation in the aortic part of the DA was not affected by NOX inhibitors.

Conclusions Our data indicate that PPP and NADPH oxidase activation are events involved in the signalling cascade ofnormoxic contraction of chicken DA.

\section{PO-511 WITHDRAWN}

\section{PO-0512 MICROVASCULAR CIRCULATORY DYSREGULATION: A NEW PARADIGM FOR CARDIOVASCULAR COMPROMISE IN THE PRETERM NEWBORN}

${ }^{1}$ Wright, ${ }^{2} \mathrm{R}$ Dyson, ${ }^{3} \mathrm{M}$ Berry, ${ }^{4} \mathrm{~B}$ Lingwood. ${ }^{1}$ School of Medicine, University of Wollongong, Wollongong, Australia; ${ }^{2}$ Mother and Babies Research Centre HMRI, University of Newcastle, Newcastle, Australia; ${ }^{3}$ Wellington School of Medicine, University of Otago, Wellington, New Zealand; ${ }^{4}$ Perinatal Research Centre, University of Queensland Centre for Clinical Research, Brisbane, Australia

10.1136/archdischild-2014-307384.1155 